\title{
Advances in Primate Community Ecology Research Across Spatial, Temporal, and Phylogenetic Scales
}

\author{
Jason M. Kamilar • Lydia Beaudrot • Kaye E. Reed
}

Received: 17 July 2014 / Accepted: 18 July 2014 / Published online: 14 October 2014

(C) Springer Science+Business Media New York 2014

Understanding the factors influencing the diversity of primate communities is important for studies of primate evolutionary history, primate behavioral ecology, and the development of conservation strategies. Previous research on primate communities has focused on a variety of questions including explaining variation in species richness, biomass, and taxonomic composition (Kamilar and Beaudrot 2013; Reed and Bidner 2004), but with less attention given to the role of spatial scale in structuring communities, interactions between primates and other taxa, or evolutionary history. In recent years, there have been important advances in GIS, ecological informatics, macroecology, and phylogenetics, which have enabled scientists to revisit classic questions and address new questions in community ecology. This research has focused attention on the importance of variation in spatial, temporal, and phylogenetic scales for structuring communities (Beaudrot and Marshall 2011; Beaudrot et al. 2013; Gavilanez and Stevens 2013; Kamilar and Ledogar 2011; Kamilar and Muldoon 2010; Lehman 2006).

The articles in this special issue of the International Journal of Primatology are based on a symposium at the 2013 American Association of Physical Anthropologists Meeting at Knoxville, Tennessee. The special issue includes a wide variety of perspectives to understand the diversity of primate communities across a variety of scales. The

J. M. Kamilar $(\bowtie)$

School of Human Evolution and Social Change, Arizona State University, Tempe, Arizona 85287, USA e-mail: jkamilar@midwestern.edu

J. M. Kamilar

Department of Anatomy, Arizona College of Osteopathic Medicine, Midwestern University, Glendale, Arizona, USA

L. Beaudrot

Graduate Group in Ecology and Department of Anthropology, University of California, Davis, Davis, California 95616, USA

K. E. Reed

School of Human Evolution and Social Change and Institute of Human Origins, Arizona State University, Tempe, Arizona 85287, USA 
first article, by Beaudrot and colleagues (2014), tests the idea that trade-offs between the dispersal ability and ecological specialization of species are connected to broadscale patterns of community composition. In particular, species near the equator where the climate is stable are hypothesized to be dispersal limited because they are ecological specialists and species at higher latitudes where climate variability is greater are expected to be ecological generalists, and therefore less dispersal limited. If this is true, then community similarity should be best predicted by geographic distance in equatorial regions and best predicted by climatic variables in regions far from the equator. They show that this hypothesis was supported based on a data set comprising 131 primate communities in 9 biogeographic regions throughout sub-Saharan Africa. This study nicely demonstrates that community assembly processes vary predictably across space and are contingent on the spatial extent of analysis. The next article, by Kamilar et al. 2014, also focuses on broad-scale patterns in African primate communities. The authors examine how species richness and climate (several measures of rainfall and temperature) influenced the phylogenetic structure of sub-Saharan African haplorhine and strepsirrhine communities. Examining communities at the suborder level is important because of the substantial niche differences between haplorhines and strepsirrhines. These differences may result in community structure variation that would be undetected at the order level. In fact, the authors found that the phylogenetic structure of haplorhine communities was most influenced by the species richness; larger communities contained more phylogenetically diverse species. In contrast, abiotic factors best predicted variation in the phylogenetic structure of strepsirrhine communities. This finding suggests that climate drives the occurrence of small-bodied strepsirrhines, resulting in significant changes in community composition across environmental gradients. The article by Katherine Bannar-Martin (2014) examines the possible factors driving community assembly in Malagasy communities. In particular, she examines the relative importance of environmental factors, spatial effects, and biogeographic barriers for explaining patterns of primate and nonprimate community composition. BannarMartin (2014) found that communities of primates and other arboreal mammals are best explained by spatial proximity (used as a proxy for species dispersal ability). In contrast, the composition of nonprimate and terrestrial mammals was most related to environmental factors. Interestingly, biogeographic barriers were not strongly related to the distribution of any mammal group investigated.

Two articles focus on trophic interactions involving primates. Porter et al. 2014 investigated the correlation between the phylogenetic relationships of primate species in five well-studied communities and the similarity of plant species consumed at those sites. They found that more closely related primate species exhibited high levels of dietary overlap in terms of plant species and genera consumed at all sites except for Manu. These results suggest that primates are adapted to consuming certain plant species. Primates also serve as a food source for sympatric carnivorous mammals and birds. The article by Laura Bidner (2014) reviews theory and known research related to the effects of predators on the coexistence and distribution of primate species. These "top-down" effects may be an important factor influencing polyspecific associations, primate densities, and the occurrence of primate species. In addition, she conducted a preliminary analysis suggesting that the number of preferred nonprimate mammalian prey species may be related to primate species richness. Bidner (2014) suggests that predator-prey relationships involving primates and other mammals may influence 
community structure, but stresses that more data are needed, especially related to the population densities and biomass of primates, nonprimate mammals, and their potential predators.

The next two articles, by Marshall and colleagues (2014) and Samantha Russak (2014), examine variation in community-level patterns of primates and other vertebrates over space and time within a single study site. Marshall et al. 2014 focused on 10 frugivorous vertebrates (4 primate species, 2 birds, and 4 nonprimate mammals) with overlapping diets at Gunung Palung National Park during 64 months of study. They found that the population density of all frugivores varied substantially along an elevation gradient with seven distinct forest types. This is explained by the differences in plant composition and phenology across the forest types that the authors quantified. Interestingly, orangutans were the only species that exhibited significant temporal variation in population density, and the finding suggests that orangutans respond to temporal fluctuations in fruit availability by moving across relatively large spatial scales. Russak's study focused on chimpanzees and other fauna at Issa, Ugalla, Tanzania. Instead of following specific individuals to collect behavioral and ecological data, she employed a focal patch method that monitored all animals that moved into the focal patch. One benefit of this approach is to quantify the resources used as well as the resources that were not used by the species of interest. She found that chimpanzees were found in forest patches more often than expected based on the availability of this habitat type. Other habitat types that were more commonly found at Issa may be avoided by chimpanzees because of potential dietary overlap with other animals or increased predation risk.

The final two articles in the special issue address topics relevant for understanding past primate communities. Laura Stroik (2014) presents a method that quantifies the dietary niche overlap of living primates and mammal competitors using dental traits. Because teeth are commonly found in the fossil record, this approach could be applied to fossil communities to understand the potential dietary competition among species. Finally, Ari Grossman et al. 2014 describe a catarrhine paleocommunity site, Loperot, from the Miocene of Kenya. This site is unusual compared with contemporaneous locations in East Africa because it contains a relatively large number of cercopithecoid monkeys. To understand better Loperot's diversity relative to other Miocene paleocommunities, Grossman et al. 2014 examined the importance of geography and time period for predicting catarrhine community composition in several East African paleocommunities during the Miocene. Both time and space independently predicted community composition, which suggests that speciation and extinction occurring over long time periods influences the structure of communities, as well as dispersal limitation over shorter time scales.

The articles in this special issue highlight important conceptual advances that improve our understanding of primate communities from expanding the scope of analysis to include variation in spatial, temporal, and phylogenetic scales. For example, the studies by Beaudrot et al. and Bannar-Martin identify the spatial scales at which primate dispersal limitation occurs for African and Malagasy primates; the comparative nature of these studies, i.e., across regions and taxa, suggests that arboreality may be a key driver of dispersal limitation in primates. By examining determinants of community composition within the order Primates and in comparison to nonprimate mammals, the articles by Bannar-Martin and Kamilar et al. identify the stronger influence of 
environmental conditions on strepsirrhines and nonprimate mammals than on overall primate communities. Although many studies have examined primate feeding ecology in a single-species context, the article by Porter et al. 2014 integrates feeding ecology at the community level to identify the role of phylogeny in primate foraging behavior at multiple sites. The site-specific studies of vertebrate communities by Marshall et al. and Russak identify overlap in habitat use by primates and sympatric vertebrates. Both of these studies situate our understanding of the ecological roles of primates in the context of the broader vertebrate communities in which they occur. Lastly, the articles by Stroik and Grossman illustrate the utility of using extant taxa, whether they are primates or not, as models for understanding extinct species dietary diversity (in the former article) and applying methods often used to study modern communities for addressing questions in the fossil record (in the latter article). Analyzing fossil primate communities with comparisons to modern analogs allows a better understanding of community patterns that are seen in the fossil record.

We hope that the diverse but related topics in this issue generate increased interest in primate community ecology. Knowledge of primate community ecology has important implications for a wide variety of research areas in biological anthropology, ranging from primate (including human) evolution, biogeography, and behavioral ecology to conservation biology. We believe that the research presented here informs these fields and we hope it will stimulate new ideas for future research endeavors.

Acknowledgements We thank all of the participants of the American Association of Physical Anthropologists (AAPA) symposium, with special thanks to those researchers contributing manuscripts. We thank Joanna Setchell for inviting us to edit this special issue of the International Journal of Primatology. We appreciate her support during all phases of the editorial process. In addition, Dennis Galvez and Edlyn Apolonio provided valuable editorial assistance while preparing this issue. Finally, we are grateful to all of the reviewers who provided helpful comments on the manuscripts.

\section{References}

Bannar-Martin, K. (2014). Primate and nonprimate mammal community assembly: The influence of biogeographic barriers and spatial scale. International Journal of Primatology, 35, doi:10.1007/s10764-014-9792-2.

Beaudrot, L., Kamilar, J. M., Marshall, A. J., \& Reed, K. E. (2014). African primate assemblages exhibit a latitudinal gradient in dispersal limitation. International Journal of Primatology, 35, doi:10.1007/s10764014-9773-5.

Beaudrot, L., Struebig, M. J., Meijaard, E., van Balen, B., Husson, S., \& Marshall, A. J. (2013). Co-occurrence patterns of Bornean vertebrates suggest competitive exclusion is strongest among distantly related species. Oecologia, 173, 1053-1062.

Beaudrot, L. H., \& Marshall, A. J. (2011). Primate communities are structured more by dispersal limitation than by niches. Journal of Animal Ecology, 80, 332-341.

Bidner, L. (2014). Primates on the menu: Direct and indirect effects of predation on primate communities. International Journal of Primatology, 35, doi:10.1007/s10764-014-9797-x.

Gavilanez, M. M., \& Stevens, R. D. (2013). Role of environmental, historical and spatial processes in the structure of Neotropical primate communities: Contrasting taxonomic and phylogenetic perspectives. Global Ecology and Biogeography, 22, 607-619.

Grossman, A., Liutkus-Pierce, C., Kyongo, B., \& M'Kirera, F. (2014). New fauna from Loperot contributes to the understanding of early Miocene catarrhine communities. International Journal of Primatology, 35, doi:10.1007/s10764-014-9799-8.

Kamilar, J. M., \& Beaudrot, L. (2013). Understanding primate communities: Recent developments and future directions. Evolutionary Anthropology, 22, 174-185. 
Kamilar, J. M., Beaudrot, L., \& Reed, K. E. (2014). The influences of species richness and climate on the phylogenetic structure of African haplorhine and strepsirrhine primate communities. International Journal of Primatology, 35, doi:10.1007/s10764-014-9784-2.

Kamilar, J. M., \& Ledogar, J. A. (2011). Species co-occurrence patterns and dietary resource competition in primates. American Journal of Physical Anthropology, 144, 131-139.

Kamilar, J. M., \& Muldoon, K. M. (2010). The climatic niche diversity of Malagasy primates: A phylogenetic approach. PLoS One, 5, e11073. doi:10.1371/journal.pone.0011073.

Lehman, S. M. (2006). Nested distribution patterns and the historical biogeography of the primates of Guyana. In S. M. Lehman \& J. G. Fleagle (Eds.), Primate biogeography (pp. 63-80). New York: Springer Science+Business Media.

Marshall, A. J., Beaudrot, L., \& Wittmer, H. U. (2014). Responses of primates and other frugivorous vertebrates to plant resource variability over space and time at Gunung Palung National Park. International Journal of Primatology, 35, doi:10.1007/s10764-014-9774-4.

Porter, L. M., Gilbert, C. C., \& Fleagle, J. G. (2014). Diet and phylogeny in primate communities. International Journal of Primatology, 35, doi:10.1007/s10764-014-9794-0.

Reed, K. E., \& Bidner, L. R. (2004). Primate communities: Past, present, and possible future. American Journal of Physical Anthropology, 47, 2-39.

Russak, S. M. (2014). Using patch focals to study unhabituated dry-habitat chimpanzees (Pan troglodytes schweinfurthii) and sympatric fauna at Issa, Ugalla, Tanzania. International Journal of Primatology, 35, doi:10.1007/s10764-014-9803-3.

Stroik, L. (2014). Dietary competition in an extant mammalian guild: Application of a quantitative method to evaluate reconstructed niche overlap in paleocommunities. International Journal of Primatology, 35, doi: 10.1007/s10764-014-9793-1. 